\title{
Business Education: Faculty Tips to Guide International and Domestic Student Interaction to Benefit Classroom Learning
}

\author{
Allen C. Barclay \\ Northern State University \\ Amber M. Mathern \\ Northern State University \\ Natalie A. Barclay \\ University of South Dakota \\ University College Cork
}

In the past few years, several countries have become global economic powerhouses by vastly increasing the number of middle-class populations. Because of the increase in middle-class populations, earning a college degree has become more attainable. A large number of international students have acquired enough personal wealth creating a strong expansion in global higher education. The focus of this paper is to integrate international students to bring out the best for every student in the classroom. This paper intends to address and identify steps, or tips, to best engage students from all over the world with students from the host country.

Keywords: Business Education, Student Interaction, Student Engagement

\section{INTRODUCTION}

Collectively, two of the authors of this paper have been teaching business courses at a small liberal arts university in the upper Midwest region of the United States (U.S.) for over five years. Their university has a modest population of international students representing over 40 countries from all over the world. They each normally have a wide range of international students in our on-campus courses. For their university, it is very common for the largest percentage of these international students to study business. They are not a large business program; they average around 400 students enrolled in any given academic year. Of those, about 50 students in the business school come from all over the world. They host both study-abroad students, and international degree seeking students.

This paper intends to discuss some common challenges facing incoming study-abroad international students, some common challenges facing professors and instructors who teach these students, and finally some ideas to help foster an atmosphere of integration and learning for both the international students, and local or domestic students. 
Along with some of these ideas, the authors intend to discuss some personal experiences with studying abroad. Two authors have studied abroad as undergraduate students, in two totally different parts of the world in different decades. The third author has taught faculty led and study abroad courses in Europe, Asia, and North America. These experiences, coupled with years teaching students from all over the world have provided some insight into what works, and what does not work with integrating and promoting globalization of the classroom. Working with students who come from different cultures, nations, and programs involves multiple dimensions; however, this paper intends to focus solely on working with international students in the classroom. The authors understand that there are programs for international students on campus, dorm and housing programs, international office and staff members that work hard to provide exceptional experiences for students. Much of that is outside the scope of this paper, so the authors focus on teaching, teacher behavior, and the time these students spend in the classroom.

\section{STUDY ABROAD AND THE LITERATURE}

Numerous papers in the past have discussed study abroad and student/teacher interaction in the classroom (Sarkodie-Mensah, 1998; Zhao, Kuh and Carini, 2005; Wang and BrckaLorenz, 2018). Classroom culture and the associated challenges as they relate to international students have not drastically changed in the past twenty years. The cultural dimensions of many international students are much different from that of the home country. This has been the case all along. Tompson and Tompson (1996) suggest the informal atmosphere of many U.S. classrooms make it hard for some international students to participate completely due to the violation of their ingrained beliefs. Some of these beliefs may include professors holding a very high place in society, addressing professors in a way to include titles, honors, etc. and a non-participatory form of class lecture (Sarkodie-Mensah, 1998).

While the U.S. share of international students dropped from 28 percent in 2001 to 24 percent in 2017 , the U.S. is still a popular study destination for many international students. In 2017, the U.S. was host to approximately 1.1 million international students. There are many motivational factors for studying abroad, and research has shown that academic goals are the most prominent factor (Choudaha \& Chang, 2012). To that end, faculty may help international students achieve their academic goals. A sense of belonging has been known to significantly enhance international students' academic performance (Glass, Gómez, \& Urzua, 2014). Sense of belonging has been used as a theoretical framework to understand the motivational dynamics of interpersonal relationships between professors and international students (Glass, Kociolet, Wongtrirat, Lynch and Cong, 2015). These authors go on to suggest that professors are "among those significant persons that have the potential to fulfill or thwart this fundamental human need" (p.354).

Among other factors such as participating in leadership programs and interacting with others from their own culture, international students who take courses where professors facilitate intergroup dialogue have reported more positive perceptions of campus climate (Glass, 2012). Glass (2012) also stated:

It is not enough to simply assume meaningful cross-group dialogue that occurs because the demographic makeup of the student body is more diverse. Courses where international students engage content related to cultural and ethnic diversity foster development across the cognitive, intrapersonal, and interpersonal dimensions of selfauthorship. (p. 244)

\section{STUDENT ENGAGEMENT}

Studies have compared international student and U.S. student engagement in effective educational practices (Zhao, Kuh and Carini, 2005). Their findings indicate that international students are more engaged in some areas than the U.S. students. In addition, there was a difference in first-year international students' engagement and senior international students. It is significant to note that their study measured 
student engagement from aspects such as academic challenge, active and collaborative learning, student interaction with faculty, community service, computer technology, and relaxing and socializing.

The first-year international students score higher in areas such as academic challenge, active and collaborate learning, student-faculty interaction and technology use than their U.S. counterparts in this aspect of engagement. The study suggests the possibility that international students are more comfortable and confident using computer technology as this is one area where the international student has some control and can immediately experience success. The study (Zhao, Kuh, and Carini, 2005) identifies this form of engagement to decrease over time. However, both first-year and senior international students were less satisfied with their overall experience than the U.S. students. While this study encourages faculty members to promote the mixing of international students with those of different cultures on collaborative projects, it does not give specific recommendations or advice on how to do so.

Wang and BrckaLorenz (2018) explored international student engagement in effective learning strategies, collaborative learning, and student-faculty interaction as well as international student engagement from the perspectives of faculty and students. Effective learning strategies, when employed properly, can foster a conducive learning environment. These authors state the following:

Faculty approaches and behaviors in connecting with international students will be beneficial to the engagement of international students and students overall, especially in the student-faculty interaction. At the same time, faculty may also benefit from the engagement of international students, such as enhancing intercultural communication skills and promoting cultural awareness. (p. 1028)

Similar to the previously mentioned study from Zhao, Kuh and Carini (2005), specific recommendations for these interactions have been outlined throughout this article.

\section{STUDENT STUDY ABROAD EXPERIENCES}

From a global perspective, the notion that international students experiencing isolation and low participation in the classroom is only unique in the U.S. is not the case. Students from the U.S. also have had similar experiences as listed in the previous studies when they are studying abroad, away from their home countries. According to Tarrant, Rubin, \& Stoner (2014), "the past 25 years have witnessed growing numbers of students participating in study abroad programs of varying durations, locations, and academic foci. Most recent estimates indicate that of the approximately 270,000 U.S. students who studied abroad for academic credit in 2009-2010" (p. 141). These students too tend to become less engaged in the classroom.

Two of the authors of this paper have studied abroad as undergraduate students. Both were attending college in the U.S. and wanted to enhance their education with international experience. Each author studied in two completely different countries; however, their experiences in the classroom were surprisingly similar to each other. Even more surprisingly, their experiences were also similar to the experiences of the students in the research articles used to write this paper.

\section{Natalie's Experience}

Natalie has a great deal of international travel experience. She was nineteen years old when she applied to study abroad at University College Cork (UCC), in Ireland. As a U.S. student enrolled at the University of South Dakota (USD), she has had plenty of opportunity to travel on short faculty led programs and family trips abroad. However, the UCC study abroad program was for a full academic year without a support network of other USD students or her family. Nonetheless, as a History major and Art History minor, she was excited and anxious to study in Europe. Her program started in the fall of 2018 and at that time she hoped to learn more about her topics of study and experience the culture of Ireland. 


\section{The Good}

To Natalie, Ireland is amazing. The country, the people, the experience has all been incredibly rich. It has been very helpful that the majority of the people speak the same language as Natalie. UCC is quite a bit larger than USD with almost 5,000 international students. Because of this large number of international students, the university does an astounding job providing housing, courses, and tourist programs. Natalie has traveled all over Ireland, and some of Europe while attending UCC. These trips included organized tours of many historic and cultural locations throughout Ireland. This has allowed her to immerse herself into the Irish culture.

In addition, the housing used for international students is set up only for visiting students, so Natalie has been around other students facing similar issues as her. This is great for when she wants to be around comfortable situations and people. However, the downside is that she does not get to interact with other nationalities or the domestic Irish students.

\section{Not so Good}

In the classroom, Natalie is just another student. She goes to class, sits, and learns. There is no real connection between her and her domestic classmates from Ireland. The opportunity to share her own U.S. experiences or hear about Irish experiences just never happened. After a full academic year in Ireland, there has been absolutely no in-class interaction between her and the domestic Irish students. The tendency to teach from a lecture podium is far too often used by faculty. Although, we believe lecture is a valuable tool in the classroom, there tends to be too many missed opportunities for global conversation and international student engagement. In one course, about the Vietnam War, just the presence of U.S. American students in the classroom should have fostered some kind of discussion. As the daughter of a U.S. veteran, and granddaughter of a Vietnam War era veteran, her perspective could have proven invaluable to the conversation and course discussion.

The authors agree that there is a burden of responsibility on the student to interact and engage in the discussion, however based on many of the studies conducted, international students tend to be less engaged in the discussion and end up preferring to collaborate with peers from their same culture as themselves (Sarkodie-Mensah, 1998). There tends to be less likeliness of international students to speak up in front of a classroom full of domestic students, especially when the topic is heated or controversial, as was the Vietnam War. This also does not take into consideration the difficulties incurred by students who are taking courses in languages not native to themselves. Natalie has been lucky to take courses in English, in a nation where English is both the native language and her first language. Students who are taking courses in a non-native language tend to speak up even less (Duff, 2001).

\section{Amber's Experience}

Excited and somewhat anxious, Amber, at the time was a twenty-one-year-old U.S. college student when she arrived in Beijing, China. It was May 14, 2005, and she had enrolled in a summer study abroad experience at the China Agriculture University. As one of 6,389 U.S. students who studied in China during the 2004-2005 academic year (Institute of International Education, 2006), she yearned to grow her cultural intelligence through both academic and social interactions.

While attending college in Jamestown, ND, the University of Colorado Denver offered the opportunity for economic majors at the University of Jamestown to take classes in China through their International College Beijing (ICB) program. The ICB is a joint education program between the University of Colorado Denver (CU Denver) in Denver, CO and China Agricultural University (CAU) in Beijing, People's Republic of China. This partnership, formed in 1994, was one of the first of its kind approved by the Chinese Ministry of Education (The Regents of the University of Colorado, 2019).

\section{The Good}

In almost every way, the experience offered everything it had promised. Studying in Beijing with the opportunity to travel to Shanghai and Nanjing brought the chance to visit a few major cities, and Chinese industry leaders in each city. These leaders illustrated how their companies were structured and operated 
within the global context. Each of the cities are also cultural and financial epicenters within China and offered valuable academic growth as a study abroad student.

Her study abroad experience offered cultural and touristy experiences. These included cultural and tourist trips to the Yonghe (Lama) Temple, Summer Palace, Forbidden City, Tiananmen Square, The Great Wall, Dr. Sun Yat-Sen's Mausoleum, and Presidential Palace (Nanjing) to name a few. One evening the class also had a visit to the countryside where a local farmer and his family prepared the class an evening meal. With the family sharing their traditions and cultures, Amber highlights the meal as one of her favorite parts of her experience.

In addition, the class acquired valuable knowledge through their visits to places such as the U.S. Embassy, JP Morgan, GE Healthcare Systems, U.S.-China Business Council, U.S. Foreign Commercial Center, GM Shanghai Plant, and the Shanghai Stock Exchange. In short, both the cultural and business encounters were valuable learning tools for an undergraduate student coming from the rural Midwest of the U.S.

\section{The Regretful (Blanketed as Good)}

In this particular study abroad experience, students from the CAU did not attend her classes. The only students in her classes were the students from her home university in the U.S. In addition, her roommates were also from her home university. While this was one of those things "blanketed as good", it was actually negative in retrospect. The intent was, as an international student, it would be more comfort to have roommates and classmates known to the student. While this was true in the moment, it was unfortunate in hindsight. This did not give Amber the best chance at making friends with the Chinese students at CAU. Instead, she continued to interact with her original classmates and those from CU Denver. Interaction with Chinese students typically only occurred in large groups, leaving little one-onone interactions.

While these interactions were rarely taking place outside of the classroom, they were never taking place inside the classroom. The lack of Chinese student representation in the classroom was detrimental to the ability to build a network of friends from around the world. In addition, it did not allow for the opportunity to experience a different education style. In almost every case, the connections made in virtually every organization was an ex-pat living and working in China. It was valuable to hear experience from non-Chinese individuals making their living in a foreign country. However, it would have been a superior experience and networking chance to build connections of Chinese business executives. Lastly, the many cultural and touristy events, did not foster independence on the part of each student. Students traveled on a pre-planned excursions with little responsibility for how to make the experience happen. This was, again, promoted as a 'value'. However, it was detrimental to fostering independence in each student.

\section{Teaching International Students}

There is at least 25 years of teaching experience between two of the authors. In addition, they have international teaching experience on three different continents. All of this experience has provided valuable insight related to working with both domestic and international students within the university classroom setting.

Pascarella \& Terenzini (2005) stated "the impact of college is largely determined by individual effort and involvement in the academic, interpersonal, and extracurricular offerings on a campus" (p. 602). However, this individual effort may be enhanced by faculty who engage students within the classroom. Our thoughts are only focused on the time international students spend in the classroom. The following best practices are intended to help guide instructors to foster global learning and student engagement between domestic and international students in the arena of the classroom, where faculty have the most influence and control. According to Quaye \& Harper (2014), "those who are actively engaged in educationally purposeful activities, both inside and outside the classroom, are more likely to persist through graduation" (p. 3). 


\section{Fostering Global Learning Though Best Practices}

This focus of this paper is to create a beneficial learning environment for both domestic and international students in the classroom. As the authors have highlighted throughout this paper, for effective global learning to take place, there is a strong need for international students to become more engaged in the classroom. Based on Sarkodie-Mensah's (1998) findings, international students often feel uncomfortable participating in group-work or interacting with other students. The idea of supporting international student engagement can be found in several studies that examined the impact of studentfaculty interaction on student development (Kuh \& Hu, 2001; Umbach \& Wawrzynski, 2005).

Based on the literature related to the value of engaging international students, the authors suggest increased activities of face-to-face communication with students and/or faculty specifically designed into the syllabus. They also suggest the use of polling software for immediate response in class and then expanding on each of the topics verbally, allowing the international students to ease into the face-to-face collaboration. The students can then demonstrate their overt knowledge on the topic in order to build their confidence.

\section{BEST PRACTICES}

\section{Create an Active Learning Environment}

Create an active learning environment through discussion and storytelling. This allows open dialog in the classroom. By creating a safe place for discussion, open dialog becomes an opportunity for domestic students from the host country to interact with the international students. One way to really engage with students is to teach through storytelling. According Bishop and Kimball (2006):

Storytelling is an ancient art, as old as oral communication itself. To be human is to be a storyteller; we use stories to define ourselves, to make sense of our world, and to create community. Unfortunately, educators-including teacher-librarians-have often neglected storytelling as a teaching tool and as a useful skill for students. A renewed interest in storytelling, not only by youth but also adults has resulted in storytelling associations, festivals, and clubs. As teacher-librarians, we can help keep storytelling alive in our classrooms and libraries by engaging students in storytelling activities. (p. 28)

By using storytelling, an instructor creates an atmosphere where students feel safe to engage and tell their own stories. This technique is best used by asking the students to describe a story from their own experiences that directly ties to the content being discussed. For example, discuss a concept through a story, and then ask the students to describe a time when that concept affected parts of their lives. Then ask the students to tell a story back about the same concept in their own words, related to their own experiences. Usually when it comes time for an international student to speak, they relate the story to a time back in their own country or culture. This both reinforces the concept, but also shares an international culture with the domestic students.

\section{Student Groups}

Another idea is to divide the class into groups that have both domestic students and international students. It is quite interesting to separate the international students from each other and force them to work with domestic students. Over the years, we have found that at first, the international students are appalled by the attention, however over time it really makes a difference with the engagement and interaction between all students in the classroom. According to Longmore, Dunn, and Jarboe (1996) "students derive several benefits from the group project approach. The most obvious benefit is practical, hands-on experience. Many students find that they do not thoroughly understand the concepts and ideas addressed in readings and classroom lectures until they apply them" (p. 89). This hands on experience, coupled with students feeling more comfortable communicating with each other in small groups creates a great environment for collaboration and engagement. 


\section{Globally Inclusive Assignments}

According to Lovvorn and Chen (2011), "understanding the concept of global mindset allows for an examination of the subtle differences between the multiple viewpoints of what constitutes a global mindset" (p. 276). As instructors, we can create an atmosphere where students are comfortable sharing in the discussion if they can talk about what they already know, which most often is about themselves. We can create assignments that allow students to share their own personal experiences. Students should work on small projects together, related to the chapter or content in the course. Have students relate the content to something they have experienced. This allows international students to share their culture with the rest of the class, and also provides an opportunity for international students to learn about the culture of the students from the host country. This concept of shared learning helps support further understanding of the global mindset.

\section{Flip the Classroom}

This has become a pretty common term in higher education; however, it is beneficial for students to take ownership in their own learning. The flipped classroom "is student-centered [where] each student is responsible for coming to class with a basic understanding of the material, so that she or he can fully participate and engage in class discussion" (McLaughlin, Roth, Glatt, Gharkholonarehe, Griffin, Esserman, \& Mumper, 2014, p. 236). The onus is on the student to be in control of his or her own learning. This can be done by creating assignments that have the students do work outside the classroom before the session and bring the completed work to class. From there, the instructor can facilitate discussion around what the students have already completed. Confident in what they have completed, students are more likely to participate. Once the students are in the classroom, "to facilitate learning, instructors guide students to the content, organize interactive experiences, challenge students to think creatively, and provide expert insight and feedback" (McLaughlin, et al., 2014, p. 236). The more students know about the content, the more willing they are to share in the discussion.

\section{Use of Social Media to Enhance Learning}

According to Griesemer, (2012), "the influence of social media on learning and teaching environments is growing more each year. Social media applications can reinforce class material and positively influence discussions" (p. 8-9). Students today are becoming experts at the use of social media. Instructors are finding it more difficult to remove the technology from their hands and regain student attention away from social media. However, there is a way to promote learning via these social and technological advances. Zhao, Kuh, and Carini (2005) stated "international students used computer technology more frequently in course learning activities" (p. 223). The fact that all students, regardless of where they come from tend to be on the same page as each other when dealing with social media and technology. The use of in-class polls, technology-based games like Kahoot, Poll-Everywhere, and/or other app-based programs tend to get all the student involved in the discussion. According to a study done by Wong (2017):

Both international and Chinese students love using clickers in their learning. Traditionally, it is believed that Chinese students are passive learners and seldom answer questions in class. Findings from the study pointed out that clickers help students remove language and communication barriers in class and raise their involvement in class participation. (p. 207)

Language barriers tend to fall, and students relax when they start competing with each other anonymously via technology.

\section{Problem-based Learning}

Another technique available to instructors is the concept of problem-based learning (PBL). PBL is an instructional approach that has been used successfully for over 40 years and continues to gain acceptance 
in higher education (Savory, 2006). PBL is a technique developed from constructivism, or a philosophical view of how we come to understand or know (Savery, \& Duffy, 1995) where students are in total control of their own learning. According to Savery, et al. (1995), the "knowledge evolves through social negotiation and through the evaluation of the viability of individual understandings" (p. 136). The instructor serves as a facilitator instead of a lecturer. PBL allows students to work together in groups to solve a problem or an issue assigned by the instructor based on the content of the course. As with student groups, this removes the stigma of students having to communicate their thoughts and ideas to the whole class, or to the instructor.

\section{Classroom Engagement}

Every best practice covered in this paper comes down to one basic principle, which is to continuously engage all students to share something that enlightens everyone about where they are from, both host and international students. In the book International Student Engagement: strategies for creating inclusive, connected, and purposeful campus environments, Glass, Wongtrirat, and Buus (2015) comprehensively cover how to engage students in the classroom, however they state that it is important to understand how integral international students are to the campus, the budget, and enrollment at many U.S. universities. Because of this, it is important for instructors to understand the value sitting in their own classrooms.

\section{CONCLUSION}

Natalie and Amber spent time studying abroad away from their home U.S. institutions and have each expressed their own feelings of low engagement and participation in the classroom. Their experiences were supported by the literature and findings from other researchers related to international student engagement and learning in the classroom in the U.S. and around the world. This paper intended to describe some brief examples of best practices to foster a global mindset and raise international student engagement. The purpose of this paper is to add to the literature in existence by providing some examples that may or may not work for other instructors.

As with all research, there are limits to what can be done. The authors of this paper are limited to our own personal experiences, and our courses at a U.S. university locked in the middle of country. There are no international borders near this university, so many of our host students have not traveled out of the U.S., nor do they have much interaction with populations outside of where we are located. Another limitation is the lack of an empirical study. It would be beneficial to take these ideas and test them for generalizability within the world of higher education. There is plenty of research in the past to support and provide validity to the ideas within this paper, however it would be valuable to create a research study to verify the benefits of integrating international students with host students for a well-rounded global education and in-depth cultural experience.

In line with previous research, the suggestions presented in this paper describe techniques to engage both international and domestic students for the sake of global learning and student engagement. These practices and techniques come from empirical research, years of experience in the classroom, and many trips abroad for all the authors. The authors have found that there tends to be a great benefit to all students by creating assignments and lessons that include increased use of storytelling, small group projects, culturally integrated assignments, the use of social media and technology, flipping the classroom, trying to engage the whole class, and the use of problem based learning. By focusing on the benchmarks set from past research and best practices of the authors, our purpose is to help foster an engaging learning environment for both domestic and international students in the classroom. 


\section{REFERENCES}

Barclay, R. T., Weinandt, M., \& Barclay, A. C. (2017). The Economic Impact of Study Abroad on Chinese Students and China's Gross Domestic Product. Journal of Applied Business and Economics, 19(4), 30-36.

Bishop, K., \& Kimball, M. A. (2006). Engaging students in storytelling. Teacher Librarian, 33(4), 28.

Choudaha, R., \& Chang, L. (2012). Trends in international student mobility. New York, NY: World Education Services.

Duff, P. (2001). Language, literacy, content, and (pop) culture: Challenges for ESL students in mainstream courses. Canadian Modern Language Review, 58(1), 103-132.

Glass, C. R. (2012). Educational experiences associated with international students' learning, development, and positive perceptions of campus climate. Journal of Studies in International Education, 16(3), 226-249.

Glass, C. R., Gómez, E., \& Urzua, A. (2014). Recreation, intercultural friendship, and international students' adaptation to college by region of origin. International Journal of Intercultural Relations, 42(3), 104-117.

Glass, C. R., Kociolek, E., Wongtrirat, R., Lynch, R. J., \& Cong, S. (2015). Uneven experiences: The impact of student-faculty interactions on international students' sense of belonging. Journal of International Students, 5(4), 353-367.

Glass, C. R., Wongtrirat, R., \& Buus, S. (2015). International student engagement: Strategies for creating inclusive, connected, and purposeful campus environments. Stylus Publishing, LLC.

Griesemer, J. A. (2012). Using social media to enhance students' learning experiences. Quality approaches in higher education, 3(1), 8-11.

Institute of International Education. (2006). Leading Destinations of U.S. Study Abroad Students, 2003/04-2004/05. Open Doors Report on International Educational Exchange. Retrieved from http://www.iie.org/opendoors.

Ku, G. D., \& Hu, S. (2001). The effects of student-faculty interaction in the 1990s. The Review of Higher Education, 24(3), 309-332.

Longmore, M. A., Dunn, D., \& Jarboe, G. R. (1996). Learning by doing: Group projects in research methods classes. Teaching Sociology, 24, 84-91.

Lovvorn, A. S., \& Chen, J. S. (2011). Developing a global mindset: The relationship between an international assignment and cultural intelligence. International Journal of Business and Social Science, 2(9).

McLaughlin, J. E., \& Mumper, R. J., et al. (2014). The flipped classroom: a course redesign to foster learning and engagement in a health professions school. Academic medicine, 89(2), 236-243.

Pascarella, E. T., \& Terenzini, P. T. (2005). How College, Vol. 2. Affects Students.

Quaye, S. J., \& Harper, S. R. (Eds.). (2014). Student engagement in higher education: Theoretical perspectives and practical approaches for diverse populations. Routledge.

Sarkodie-Mensah, K. (1998). International Students in the U.S.: Trends, Cultural Adjustments, and Solutions for a Better Experience. Journal of Education for Library and Information Science, $39(3), 214-222$.

Savery, J. R. (2006). Overview of problem-based learning: definition and distinctions, the interdisciplinary. Journal of Problem-based learning.

Savery, J. R., \& Duffy, T. M. (1995). Problem based learning: An instructional model and its constructivist framework. Educational technology, 35(5), 31-38.

Tarrant, M. A., Rubin, D. L., \& Stoner, L. (2014). The added value of study abroad: Fostering a global citizenry. Journal of Studies in International Education, 18(2), 141-161.

The Regents of the University of Colorado. (2019). International College Beijing. Retrieved from http://www.ucdenver.edu/academics/internationalprograms/oia/icb/Pages/default.aspx. 
Tompson, H. B., \& Tompson, G. H. (1996). Confronting Diversity Issues in the Classroom with Strategies to Improve Satisfaction and Retention of International Students. Journal of Education for Business, 72(1), 53-57.

Umbach, P. D., \& Wawrzynski (2005). Faculty do Matter: The role of college faculty in student learning and engagement. Research in Higher Education, 46(2), 153-184.

Wang, R., \& BrckaLorenz, A. (2018). International Student Engagement: An Exploration of Student and Faculty Perceptions. Journal of International Students, 8(2), 1002-1033.

Wong, A. (2016). Classroom response systems and student performance improvement: Local versus international students. Journal of Teaching in International Business, 27(4), 197-208.

Zhao, C., Kuh, G. D., \& Carini, R. M. (2005). A Comparison of International Student and American Student Engagement in Effective Educational Practices. Journal of Higher Education, 76(2), 209.

Zong, J., \& Batalova, J. (2018, May 9). International Students in the United States. Migration Information Source. Retrieved from https://www.migrationpolicy.org/article/internationalstudents-united-states. 